\section{Turf War Over Diagnostic Testing}

If you've been around as long as I have, you'll remember how excited we were to have a test introduced that helped us select treatment for patients with breast cancer. Yes, I'm talking about a humble immunohistochemistry analysis for estrogen and progesterone receptors. Not only did this give us some prognostic information but it defined for us the use of hormone therapy. I confess, I never wondered about the source of the antibody used, the validity of the cutoff for the interpretation, or the extent of prior clinical correlation. I just trusted it. My, how times have changed!

The FDA has had authority over in vitro diagnostics for a long time. But it has never broadly enforced this. Most tests we use are not FDA-approved. In fact, the conditions under which tests are performed — CLIA (Clinical Laboratory Improvement Amendments) —are overseen by the Centers for Medicare \& Medicaid Services. CLIA requires standardized conditions for testing so the tests are precise and reproducible. But it doesn't require tests to be useful. Usefulness is up to us to decide by reading the literature. And we're used to falsepositives and false-negatives, so we try to align findings into clinical context. That's called the "art of medicine." But, because of the growth in precision medicine, more and more diagnostics are being introduced and the stakes are getting higher.

Now the FDA is getting more serious about diagnostics. Last July, the FDA announced proposed regulations ${ }^{1}$ for laboratory tests that are risk-based. High- and moderate-risk tests, such as those that tell you how to treat or whether to treat a patient with cancer, would fall into this category. Already we are seeing pharmaceutical companies positioning drugs in development to be aligned with an appropriate diagnostic. In fact, last month the FDA simultaneously approved olaparib (a PARP inhibitor) with a test for BRCA mutations for the management of ovarian cancer.

In case you are wondering, the process of validating a biomarker for clinical utility can be very expensive and time-consuming. The NIH guidelines on biomarker development and validation ${ }^{2}$ are dizzyingly complex. Many of the assays will be tissue-based, and the process of building clinically annotated biorepositories is costly and complicated. So these regulations will add to the cost of drug development, I'm sure. It might even add time to the process, delaying drug approval. But I think this investment is worth it.

If we're serious about precision medicine, we should put just as much thought and care into the tools that direct our actions as we do into the drugs we choose or avoid. Anything we can do to improve our outcomes through appropriate diagnostics will also help curb the cost of care and add value. And I wouldn't stop at in vitro diagnostics. What about devices? For example, we have numerous devices to freeze, fry, or radioablate tumors, and these techniques are often applied to metastatic sites. The evidence base just isn't there to support this one way or another. Shouldn't it be? It would be, if the FDA demanded it.

When I was a member of the Oncologic Drugs Advisory Committee for the FDA, I developed a deep appreciation for the organization. This part of our government actually works. And it accomplishes a lot with a lean budget. The Association for Molecular Pathology has issued a statement broadly opposing the FDA in this new effort. ${ }^{3}$ They have legitimate concerns, but I disagree with their opposition. I don't think we should argue about whether the FDA should exercise their authority over in vitro diagnostics. They should! And we should endorse their effort and give them the resources they deserve to do this right.

\section{References}

1. FDA. Draft Guidance for Industry, Food and Drug Administration Staff, and Clinical Laboratories; Framework for Regulatory Oversight of Laboratory Developed Tests (LDTs). Bethesda, MD; 2014. Available at http://www.fda.gov/ downloads/medicaldevices/deviceregulationandguidance/guidancedocuments/ucm416685.pdf. Accessed March 16, 2015.

2. National Institutes of Health. Development and Validation of Disease Biomarkers (R01). Rockville, MD, 2009. Available at http://grants.nih.gov/grants/guide/pa-files/PA-09-204.html. Accessed March 16, 2015.

3. Association of Molecular Pathology. AMP Submits Written Comments to FDA on Proposed Regulation of Laboratory Developed Tests. Press Release. Bethesda, MD; 2015. Available at http://www.amp.org/documents/20150202 AMPSubmitsCommentstoFDAonLDTRegulation.pdf Accessed March 16, 2015.

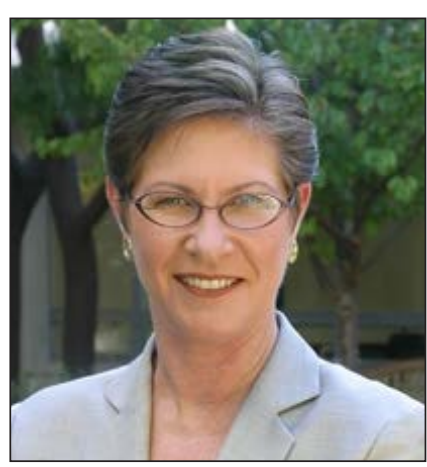

Margaret Tempero, MD

Dr. Tempero is a Professor of Medicine and Director of the UCSF Pancreas Center, and the editor-in-chief of JNCCN. Her research career has focused on pancreatic ductal adenocarcinoma especially in the area of investigational therapeutics. Dr. Tempero has served on the ASCO Board of Directors and as ASCO President. She co-directed the AACR/ASCO Methods in Clinical Cancer Research and taught this course and similar courses in Europe and Australia. She was founding Chair of the $\mathrm{NCl}$ Clinical Oncology Study Section (CONC) and served as a member and chair of the $\mathrm{NCI}$ Board of Scientific Counselors Subcommittee $A$. She is on the External Advisory Boards of the Pancreas SPOREs at Mayo Clinic and at $U A B / M i n n e s o t a$ and the GI SPORE at the University of Arizona. She is, or has been, on the Scientific Advisory Boards of the Lustgarten Foundation, the Pancreatic Cancer Action Network, the V Foundation, The Alberta Canada Cancer Board, and the EORTC. She served as a member of the Oncology Drug Advisory Committee for the FDA.

She has served as Deputy Director and Interim Director for the UNMC Eppley Cancer Center. She is Chief Emeritus of the Division of Medical Oncology at UCSF and served as Deputy Director and Director of Research Programs at the UCSF Helen Diller Family Comprehensive Cancer Center.

The ideas and viewpoints expressed in this editorial are those of the author and do not necessarily represent any policy, position, or program of NCCN. 